\title{
Theoretical study of the aspect ratio of a solar still with double slopes
}

\author{
A.Madhlopa ${ }^{1, *}$, J.A. Clarke ${ }^{1}$ \\ ${ }^{1}$ Energy Systems Research Unit, University of Strathclyde, James Weir Building, 75 Montrose Street, Glasgow \\ G1 1 XJ, United Kingdom. \\ * Corresponding author. Tel: +44 1415483204, Fax: +44 141548, E-mail:a.madhlopa@strath.ac.uk
}

\begin{abstract}
Clean water is essential for good health which influences the social and economic development of any nation. However, there is limited access to safe water on a global scale. This challenge can be overcome through a multi-faceted approach, including the development of appropriate technologies for water treatment and decision-making tools. Solar distillation is one of the commonest non-conventional methods for improving the quality of water. In this vein, the most widely-exploited solar distillation system is a conventional solar still, which has a thin layer of saline water in a shallow basin with a transparent cover over the water and one or two slopes. The productivity of a solar distillation system is influenced by design, climatic and operational factors, with solar radiation being the most influential meteorological parameter. It is therefore necessary to optimize solar radiation that effectively reaches the base of the solar still. Previous attempts have sought to improve the design characteristics of conventional solar stills through the consideration of system geometry and optical properties of construction materials. One of the important geometric parameters is the ratio (R) of length to width (aspect ratio) of the still base. For a single-slope solar still (SSS), R has been examined in preceding studies. Nevertheless, there is a paucity of information on the aspect ratio of a double-slope solar still. In this study, a state-of-the-art software (ESP-r) was used to simulate the variation of effective insolation with R for a double-slope solar still (DSS) in the east-west and north-south orientations and a SSS facing south. Meteorological data captured at the University of Strathclyde $\left(55^{\circ} 52^{\prime} \mathrm{N}, 4^{\circ} 15^{\prime} \mathrm{W}\right)$ and Guantanamo Bay $\left(19^{\circ}\right.$ $54^{\prime} \mathrm{N}, 14^{\circ} 51^{\prime} \mathrm{E}$ ) was employed in this analysis. Simulation results show that the optical performance of a DSS was lower (in both orientations) than that of a SSS at both sites. The DSS collected more solar energy in the eastwest than north-south orientation, for a given value of R. In addition, effective insolation increased with $\mathrm{R}$ to an optimum level for both the DSS and SSS. Approximate optimum values of R were 3.0 and 2.0 for the University of Strathclyde and Guantanamo Bay respectively. However, the optimum value of $\mathrm{R}$ was not sensitive to the orientation of the DSS at the two sites. Further, the DSS and SSS exhibited the same optimal value of R at a specific site. It appears that R significantly affects solar collection in a DSS.
\end{abstract}

Keywords: Aspect ratio, Effective insolation.

\section{Nomenclature}

A area of still base $m^{2}$

$B$ width of still base. .. $m$

$G$ irradiance $\mathrm{Wm}^{-2}$

$H \quad$ mean annual daily effective insolation $\mathrm{Jm}^{-2}$

I hourly effective insolation ..................... $\mathrm{Jm}^{-2}$

$L \quad$ length of still base................................. $m$

Q solar gain ........................................... (\%)

$R \quad$ aspect ratio .......................... dimensionless

$x \quad$ distance along $x$-axis ............................(m)

$y \quad$ distance along $y$-axis ...........................(m)

$\mathrm{z} \quad$ distance along $\mathrm{z}$-axis .............................(m)

$\alpha$ absorptance .......................... dimensionless

$\beta \quad$ tilt angle........................................ degree $\phi \quad$ latitude........................................... degree

$\theta \quad$ zenith angle ........................................degree

$\rho$ reflectance ........................... dimensionless

$\tau$ solar direct transmittance ... dimensionless

Subscripts

1 transparent cover 1

2 transparent cover 2

$b$ basin liner

$g$ ground

w wall

\section{Introduction}

Clean water is essential for good health which influences the social and economic development of any nation. However, a large proportion of the available water on the earth's surface is saline [1]. This problem is exacerbated by environmental pollution predominantly 
caused by anthropogenic activities. Consequently, there is limited access to clean water, especially in developing countries [2]. Solar distillation is one method of producing fresh water from salty water.

A conventional solar still is the most-widely exploited solar distillation system. It has a thin layer of water in a horizontal basin, transparent cover over the water with one or two slopes (Fig.1). The single-slope solar still (SSS) has a back wall which acts as an internal reflector while the double-slope solar still (DSS) has no back wall. Transparent covers in a DSS may be symmetrical $\left(\beta_{1}=\beta_{2}\right)$ or symmetrical $\left(\beta_{1} \neq \beta_{2}\right)$, with a gable along each breadth. In both the SSS and DSS, saline water in the basin is heated by solar radiation passing through the transparent cover and absorbed by the water and bottom part of the still basin. Vapour flows upwards from the hot water and condenses when it comes into contact with the cooler inner surface of the transparent cover. The condensate (clean water) is collected in a channel fitted along the lower edge of the transparent cover. For a given set of system design parameters, the distillate output from the system is influenced by climatic and operational factors, and a SSS intercepts a higher proportion of solar radiation than a DSS at locations with both high and low latitudes [3]. Moreover, solar radiation is the most influential environmental parameter [4], and the DSS is economically more viable than the SSS [5]. So, it is necessary to optimize the design of the DSS in order to maximize its capability of solar collection.

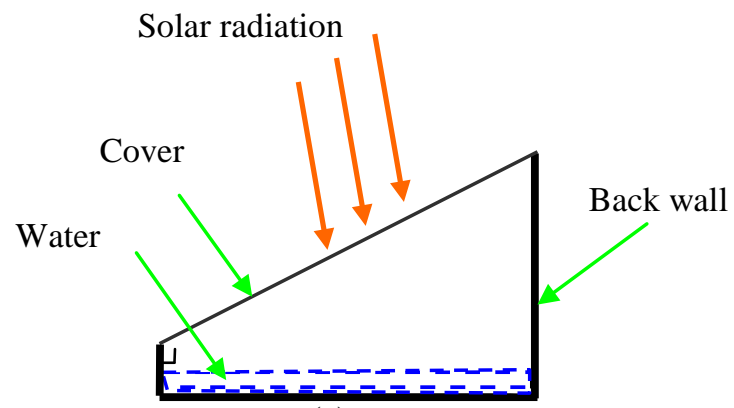

(a)

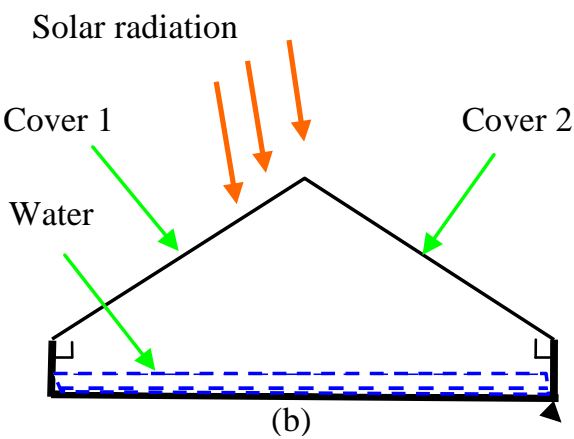

(b)

Fig.1: Cross-section of a basic solar still with a) single slope and b) double slopes.

Attempts have been made to establish materials with suitable optical properties of various components of a basin-type solar still. The cover absorbs and reflects part of the incoming solar radiation, with the remaining fraction being transmitted onto the still walls, the surface of saline water and basin liner. So, transmittance is the most important optical property of the cover layer, which may be plastic or glass. Different cover materials for solar stills have been investigated in previous work [6, 7]. It was found that solar stills with glass covers perform better than those with plastic covers. In addition, the internal surfaces of the walls of the still absorb and reflect part of the received solar radiation onto the surface of water. The reflectance of the walls of a solar still influences the effective insolation on saline water in the basin [8]. The basin liner also absorbs part of the solar radiation intercepted by the transparent cover. Consequently, the absorptance of the basin liner is an essential optical property. The various still components are assembled into a structure with specific geometry which affects the optical performance of the distillation system.

A solar still may be mounted on a tracker or fixed plane. A tracking solar still follows the sun on daily (one-axis) or daily and seasonal (two-axis) basis to maintain a low angle of incidence and thereby increase the transmission of solar radiation through the transparent cover. However, tracking solar systems are costly and unsuitable for large-scale production of 
distilled water. In contrast, there is no cost associated with tracking in stationary solar stills. So, this variety of solar stills is more feasible for practical applications. The transparent cover of a fixed solar still is inclined at an angle $(\beta)$ to the horizontal plane. It is reported that the optimum value of $\beta$ is $10^{\circ}$ which just enables the distillate to flow downwards on the inner surface of the cover without dropping back into the basin $[3,9]$. Nevertheless, $\beta$ also affects the transmission of solar radiation through the cover [10]. So, $\beta>10^{\circ}$ is sometimes used depending on the latitude $(\phi)$ of the site [4]. Generally, $\beta=\phi-10^{\circ}$ for summer season $\left(\phi>10^{\circ}\right)$, $\beta=\phi$ for annual performance and $\beta=\phi+10^{\circ}$ for winter season [11]. In addition, a stationary DSS is oriented with the covers facing the east and west directions to optimize solar collection $[12,13]$. On the other hand, a stationary SSS is commonly mounted facing the Equator for optimum performance. Capture of solar energy is also affected by the ratio of the length to width of the still base (R). Optimization of R is reported for a SSS [14] but there is a paucity of information on the aspect ratio of a DSS. The objective of this study was therefore to overcome this limitation

$\mathrm{R}=\mathrm{L} / \mathrm{B}$

\section{Methodology}

\subsection{System description and computational tool}

Solar collection in a DSS with symmetrical slopes and a SSS has been studied theoretically. The major components of the systems were a) a horizontal basin, b) transparent covers and c) opaque walls and base (Fig.1).The basin liner was constructed from a steel material $(0.001 \mathrm{~m}$ thick) while the covers were constructed from clear float glass ( $0.004 \mathrm{~m}$ thick) to allow solar radiation reach the internal surfaces of the still. Each cover was inclined at $55.9^{\circ}$ to the horizontal at the University of Strathclyde $\left(55^{\circ} 52^{\prime} \mathrm{N}, 4^{\circ} 15^{\prime} \mathrm{W}\right)$ and $19.9^{\circ}$ to the horizontal at Guantanamo Bay $\left(19^{\circ} 54^{\prime} \mathrm{N}, 14^{\circ} 51^{\prime} \mathrm{E}\right)$ to optimize solar collection on annual basis. The same slope was used for the DSS and SSS at a given site. Each wall was triple-layered with expanded polystyrene $(0.05 \mathrm{~m}$ thick $)$ sandwiched between two plywood layers $(0.005 \mathrm{~m}$ thick, each layer). Similarly, the base of each still was also triple-layered with plywood external ( $0.005 \mathrm{~m}$ thick), expanded polystyrene middle ( $0.05 \mathrm{~m}$ thick) and steel internal layers. The surface area of the base remained constant for different values of the aspect ratio. In addition, the height of the lower vertical sides was fixed at $0.05 \mathrm{~m}$ above the still base while the height of the higher vertical sides varied with R. Other design parameters are presented in Table 1.

\begin{tabular}{ccc}
\multicolumn{3}{c}{ Table 1. Design parameters of a double-slope solar still. } \\
\hline Parameter & Unit & Value \\
\hline $\mathrm{A}$ & $\mathrm{m}^{2}$ & 1.00 \\
$\alpha_{\mathrm{b}}$ & dimensionless & 0.90 \\
$\rho_{\mathrm{g}}$ & dimensionless & 0.2 \\
$\rho_{\mathrm{w}}$ & dimensionless & 0.2 \\
$\tau_{1}, \tau_{2}$ & dimensionless & 0.837 \\
\hline
\end{tabular}

A state-of-the-art software (ESP-r, version11.9) was used to compute hourly irradiance on the basin liners of the DSS and SSS. This software has a robust algorithm for computation of insolation and shading effects [15]. Beam and diffuse components of solar radiation are treated separately, and optical view factors and multiple reflections are taken into consideration. A geometric construction of each solar distillation system was made in ESP-r with the origin at $\mathrm{x}=0, \mathrm{y}=0$ and $\mathrm{z}=1 \mathrm{~m}$ to simulate the system in a mounted mode (the $\mathrm{x}-, \mathrm{y}-$ and $z$-axes are mutually perpendicular, z-axis is vertical and $x-y$ plane is horizontal). The still 
base was in the $x-y$ plane, with the diagonals of the base intersecting at the origin. The orientation of the DSS was varied by rotating the system about the vertical axis through the origin ( $\mathrm{x}=0$ and $\mathrm{y}=0$ ). For each system configuration, view factors were calculated by using the ray tracing technique, and the computed optical view factors were used in the computation of effective irradiance on the base of the solar still in any given hour. The DSS was simulated with the covers oriented in the east-west and north-south directions while the SSS faced south at both sites. Effective hourly insolation $\left(\mathrm{I}_{\mathrm{i}}\right)$ was computed from irradiance on each still base. The total annual effective insolation (E) was determined by summing up the hourly insolation for a given value of the aspect ratio $(R)$. Then, the mean annual daily insolation $(H)$ was computed from $\mathrm{E}$. In addition, the area of the still base remained constant as $\mathrm{R}$ was varied from 0.5 to 4.0. At successive increments in $R$, the percentage solar gain (Q) was calculated. Equations for these calculations were as follows:

$\mathrm{I}_{\mathrm{i}}=3600 \mathrm{G}_{\mathrm{i}}$ for $\mathrm{i}=1,2,3, \ldots, \mathrm{m}$

where $\mathrm{m}=$ number of hours in a year.

$$
\mathrm{E}=\sum_{i=1}^{i=m} I_{i}
$$

$\mathrm{H}=\mathrm{E} / \mathrm{j}$

where $\mathrm{j}=$ number of days in a year.

$\mathrm{Q}_{\mathrm{k}}=100\left(\mathrm{H}_{\mathrm{k}}-\mathrm{H}_{\mathrm{k}-1}\right) / \mathrm{H}_{\mathrm{i}}$, for $\mathrm{k}=1,2,3, \ldots$

Mean hourly normal-incident beam and diffuse irradiance data, captured at the University of Strathclyde and Guantanamo Bay, was used in this study. This data covered the periods from 1 January to 31 December 2001 at the University of Strathclyde and 1 January to 31 December 1971 Guantanamo Bay. It should be noted that the University of Strathclyde and Guantanamo Bay are at high and low latitudes respectively.

\subsection{Some assumptions}

The following assumptions were made:

a) the distribution of incoming diffuse radiation was anisotropic. So, an anisotropic model was employed in calculating the amount of diffuse radiation received by a given surface. It should be mentioned that anisotropic models are more accurate in estimation of diffuse radiation than isotropic models [16],

b) the ground reflected diffusely because it is rough and so the reflected radiation is scattered,

c) the basin liner was black on the interior surface to optimize solar absorption on the still base, and

d) the solar still was not obstructed by other structures within the vicinity to reduce the effect of shading from these structures.

\section{Results and discussion}

The variation of mean annual daily effective insolation $(\mathrm{H})$ on the base of the DSS and SSS simulated at the University of Strathclyde is shown in Fig.2. It is observed that the DSS collects less solar radiation than the SSS for a given value of the aspect ratio (R). This observation is attributed to the presence of a back wall in the SSS. The back wall reflects part of the incoming solar radiation onto the still base [8]. Garg and Mann [3] also found that the 
DSS was optically less efficient than the SSS. In addition, the DSS captures more solar radiation in the east-west orientation than the north-south orientation, probably due to the effect of shading from the gables. For the east-west orientation, the gables are on the north and south of the still. So, one of these gables would cast a shadow on the still base when the sun is due north or south of the solar still, except when the sun traverses the sky over the local latitude. The sun traverses the sky to the south of the University of Strathclyde throughout the year. In this case, the southern gable would cast a shadow on the still base. However, solar radiation would be able to directly reach the still base even at low solar altitudes in the morning or afternoon. For the north-west orientation, the gables are on the east and west of the still. Thus, one of the gables would cast a shadow on the still base in the morning or afternoon times, except at local solar noon. The effect of shading is significant at low solar altitudes in the morning or afternoon, which accounts for the observed effect of orientation on the optical efficiency of the DSS [12, 13].

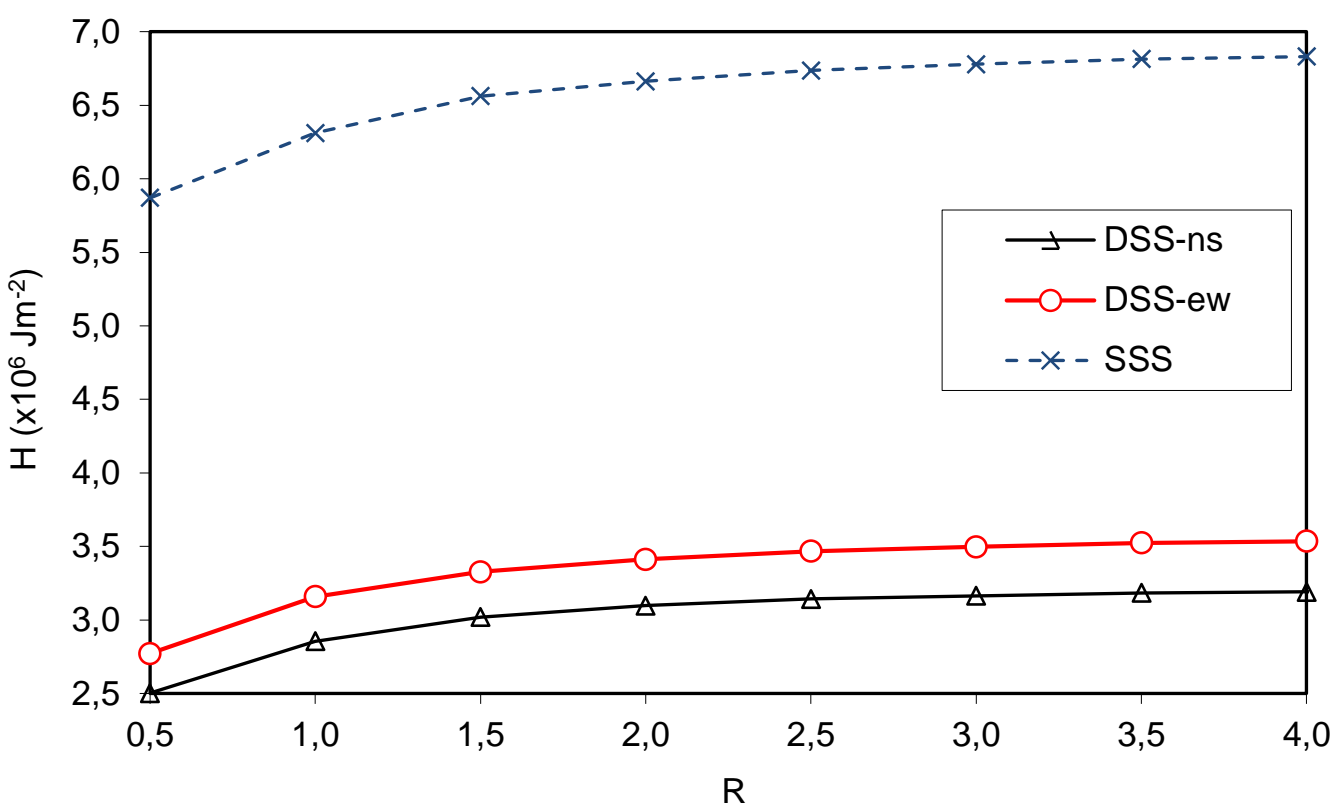

Fig. 2. Variation of mean annual daily effective insolation $(H)$ with aspect ratio $(R)$ for the DSS oriented east-west (DSS-ew) and north-south (DSS-ns), and the SSS facing south at the University of Strathclyde.

Fig.2 also shows that $\mathrm{H}$ increases with the aspect ratio $(\mathrm{R})$ of the still base to an optimum level for both the DSS and SSS. This observation is ascribed to a reduction in self-shading arising from the wall along the breadth of the stills. It should be mentioned that $\mathrm{R}$ increases as the width (B) of the still decreases, leading to a decrease in the height and area of the slanted wall of the still (for a constant slope) and its shading effect on the internal part of the still base in both the DSS and SSS. Under the prevailing meteorological conditions, the optimum value of R (when Q<1.0 \%) was approximately 3.0 for the DSS (in both the east-west and northsouth orientations) and SSS. For the SSS, El-Swify et al. [14] reported an approximate optimum value of $\mathrm{R}=2.0$ for climate data from Cairo $\left(30^{\circ} 3^{\prime} \mathrm{N}, 31^{\circ} 10^{\prime} \mathrm{E}\right)$, which is lower than the present optimum value probably due to variations in site parameters. The latitude and longitude of a site affect solar angles and the distribution of solar radiation in a still.

Fig. 3 shows the variation of $\mathrm{H}$ on the base of the DSS and SSS for the climate data from Guantanamo Bay. It is again observed that the DSS collects less solar energy than the SSS for a given value of R. In addition, the DSS captures more solar radiation in the east-west 
orientation than the north-south orientation, in agreement with results for the climate data from the University of Strathclyde. For the east-west orientation, one of the gables would cast a shadow on the still base when the sun is due north or south of the solar still, except when the sun traverses the sky over the local latitude. It should nevertheless be noted that the sun traverses the sky over head, to the south and north of Guantanamo Bay during certain times of the year. In this case, a gable would cast a shadow on the still base when the sun is not crossing the sky over head but beam radiation would be able to directly reach the still base even at low solar altitudes in the morning or afternoon. For the north-west orientation, one of the gables would cast a shadow on the still base in the morning or afternoon times, except at local solar noon. Solar radiation would be unable to directly reach the still base at low solar altitudes during certain times in the morning or afternoon, which accounts for the observed effect of orientation on the optical efficiency of the DSS.

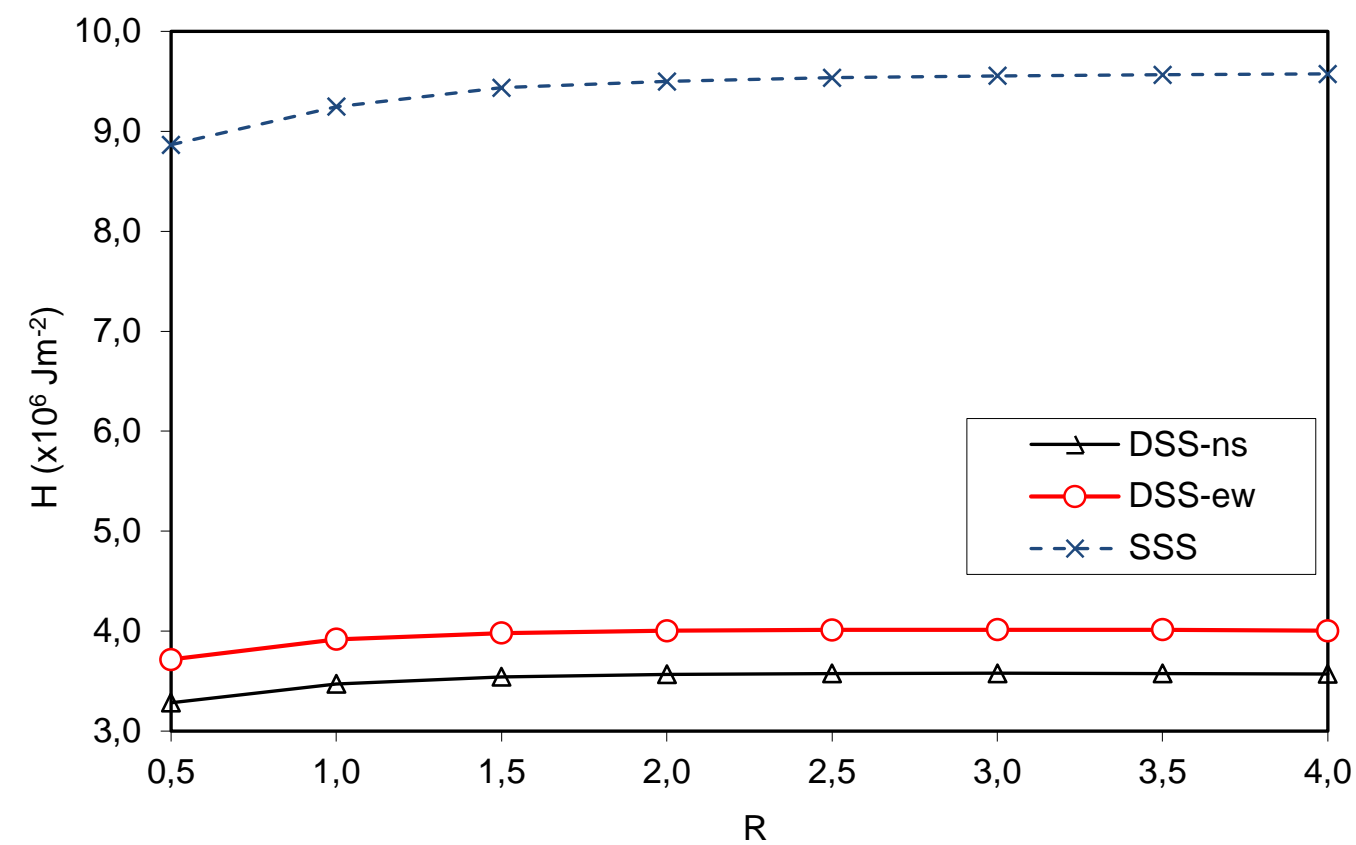

Fig.3. Variation of mean annual daily effective insolation $(H)$ with aspect ratio $(R)$ for the DSS oriented east-west (DSS-ew) and north-south (DSS-ns), and the SSS facing south at Guantanamo Bay.

It is also observed from Fig.3 that $\mathrm{H}$ increases with $\mathrm{R}$ to an optimum level for both the DSS and SSS. This observation is again attributed to a reduction in self-shading arising from the walls along the width of the stills. Under the prevailing meteorological conditions, the optimum value of $\mathrm{R}$ (when $\mathrm{Q}<1.0 \%$ ) was approximately 2.0 for the DSS (in both the eastwest and north-south orientations) and SSS, which is in close conformity with findings of ElSwify et al. [14]. This observation is probably because of the influence of site parameters. The the latitude of Guantanamo $\left(19^{\circ} 54^{\prime} \mathrm{N}\right)$ is closer to that of Cairo $\left(30^{\circ} 3^{\prime} \mathrm{N}\right)$. It should be mentioned that the zenith angle $(\theta)$ is low around solar noon during most of the days at low latitude, with $\theta=0$ at solar noon during some days of the year. Low values of $\theta$ would tend to reduce the effect of shading and optimal values of $\mathrm{R}$. In contrast, $\theta$ is relatively high around solar noon during most of the days at high latitude, with $\theta>0$ at solar noon throughout the year. High values of $\theta$ would tend to increase the effect of shading and optimal values of $\mathrm{R}$. These findings show that site parameters influence the optimum value of $\mathrm{R}$. 


\section{Concluding remarks}

The effect of aspect ratio (R) on solar collection in a double-slope solar still (DSS) has been simulated by using ESP-r software. Optical performances of the DSS and single-slope solar still (SSS) were compared under the same meteorological conditions. The DSS was studied with its transparent covers facing the east-west and north-south directions while the SSS faced south. Meteorological data captured at the University of Strathclyde (high latitude) and Guantanamo Bay (low latitude) was employed in this analysis. Simulation results show that the optical performance of a DSS (in both orientations) was lower than that of a SSS at these sites. The DSS collected more solar energy in the east-west than north-south orientation, for a given value of $\mathrm{R}$. In addition, effective insolation increased with $\mathrm{R}$ but the increase was insignificant for values of R>3.0 for both the DSS and SSS at a high latitude. Similarly, effective insolation increased with $\mathrm{R}$ but the increase was insignificant for values of $\mathrm{R}>2.0$ for both the DSS and SSS at a low latitude. It is therefore concluded that a) R significantly affects the collection of solar energy by a DSS, b) the approximate optimum value of $\mathrm{R}$ is sensitive to site parameters, c) the orientation of the DSS does not affect the optimum value of $\mathrm{R}$, and d) the optimum value of R is approximately the same for the DSS and SSS at a given site.

\section{Acknowledgements}

Authors are grateful to Newton International Fellowships Scheme for the financial support.

\section{References}

[1] G.N. Tiwari, H.N. Singh, R. Tripathi, Present status of solar distillation, Solar Energy 75, 2003, pp.367-373.

[2] WHO, World Health Statistics 2008, World Health Organization, 2008.

[3] H.P. Garg, H.S. Mann, Effect of climatic, operational and design parameters on the year round performance of single-sloped and double-sloped solar still, under Indian arid zone conditions. Solar Energy 18, 1976, pp.159-164.

[4] A.S. Nafey, M. Abdelkader, A. Abdelmotalip, A.A. Mabrouk, Parameters affecting solar still productivity. Energy Conversion and Management 41, 2000, pp.1797-1809.

[5] K. Mukherjee, G.N. Tiwari, Economic analysis of various designs of. conventional solar stills. Energy Conversion and Management 26, 1986, pp.155-157.

[6] B.W. Tleimat, E.D. Howe. Comparison of plastic and glass condensing covers for solar stills. Solar Energy 12, 1969, pp.293-304.

[7] H.M. Qiblawey, M. Banat, Solar thermal desalination technologies. Desalination 220, 2008, pp.633-644.

[8] R. Tripathi, G.N. Tiwari, Performance evaluation of solar still by using the concept of solar fraction. Desalination 169, pp.2004, 69-80.

[9] P.I. Cooper, W.R.W. Read, Design philosophy and operating experience for Australian stills. Solar Energy 16, 1974, pp.1-8.

[10] P.I. Cooper, The absorption of radiation in solar stills, Solar Energy 12, 1969, pp.333346.

[11] M.A. Samee, U.K. Mirza, T. Majeed, N. Ahmad. Design and performance of a simple solar still. Renewable and Sustainable Energy Reviews 11, 2007, pp.543-549. 
[12] A.K. Singh, G.N. Tiwari, P.B. Sharma, E. Khan, Optimization of orientation for higher yield solar still for a given location, Energy Conversion and Management 36, 1995, pp.175-187.

[13] V.K. Dwivedi , G.N. Tiwari, Experimental validation of thermal model of a double slope active solar still under natural circulation mode, Desalination 250, 2010, pp.49-55

[14] M.E. El-Swify, M.Z. Metias, Performance of double exposure still, Renewable Energy 26, 2002, pp.531-547.

[15] J.A. Clarke, Energy simulation in building design, Butterworth-Heinemann, $2^{\text {nd }}$ edition, 2001, pp.212-255.

[16] R. Perez, P. Ineichen, R. Seals, J. Michalsky, R. Stewart, Modelling daylight availability and irradiance components from direct and global irradiance, Solar Energy 44, 1990, pp.271-289. 